\title{
EL MOVIMIENTO ANTILIBERAL MALLORQUIN DE 1813
}

\author{
Antonio Moliner Prada \\ Universidad Autónoma de Barcelona
}

1. - ANTECEDENTES:

SITUACION DE LA IGLESIA MALLORQUINA

Tanto Palma como Cádiz fueron las únicas ciudades españolas libres permanentemente de enemigos durante la guerra contra el francés, en donde se produjo una mayor fermentación intelectual y política. Miguel de los Santos Oliver ha señalado que en Mallorca individuos y colectividades exteriorizaron con fidelidad y franqueza la íntima manera de ser de la sociedad española en aquellos días, puesto que a diferencia de Cádiz se hallaba exenta de las sugestiones exclusivas de toda Corte (1). En Mallorca las luchas políticas tomaron un cariz virulento que no tuvieron en otras partes de España, debido a que los inmigrados penínsulares encontraron alli un campo propicio para su expresión ideológica. Su afluencia fue masiva desde 1810, contabilizándose unos 30.000 refugiados a finales de 1812, de entre ellos tres mil frailes, 9 obispos, aristócratas y burgueses catalanes, que tuvieron una actuación destacada en la vida mallorquina durante estos años. El papel jugado por los religiosos fue decisivo en las polémicas entre serviles y liberales.

Se han hecho algunos estimaciones para calcular el poder económico de los eclesiásticos en la España del Antiguo Régimen. Según P. Vilar,

(1) DE LOS SANTOS OLIVER, M. Mallorca durante la primera revolución 1808-14. Palma, imprenta Amengual y Muntaner, 1901, p. VIII. 
partiendo de las cifras del catastro de Ensenada, a mediados del siglo XVIII el clero percibía periódicamente entre un sexto y un quinto de los ingresos globales (2). Ciertamente las órdenes religiosas poseian inmensas propiedades, que no se habían adaptado a las transformaciones de la agricultura a lo largo del siglo XVIII, y se opusieron a la presión fiscal a la que fueron sometidas a partir de 1760 y a las reformas que emprendieron las Cortes de Cádiz, aunque en realidad éstas no se plantearon la cuestión de la desamortización de los bienes del clero secular y tan sólo decretaron una tímida desamortización de los bienes de las comunidades religiosas extinguidas o reformadas por el gobierno de José I (3).

Respecto a Mallorca su número era importante y también sus riquezas. Las principales órdenes religosas instaladas en la Isla, las primeràs en el siglo XIII, fueron los dominicos, franciscanos, cistercienses, cartujos,. carmelitas, agustinos, capuchinos, teatinos, mercedrios, jesuítas y trinitarios, por citar las más importantes (4). La ciudad de Palma albergaba a la mayoría del clero regular, así por ejemplo según el padrón de 1787 las órdenes religiosas masculinas contaban con 14 conventos y un total de 745 miembros y las femeninas con 10 casas y 520 miembros, representando entre ambas un $3^{\prime} 7 \%$ del total de la población de la ciudad sin contar el clero secular (5). Durante el siglo XVIII ocho de los principales conventos de la ciudad, incluyendo la Cartuja de Valldemossa, poseían 232 propiedad-es, evaluándose sus bienes sin cargas en 527.327 libras mallorquinas:

Conventos Propiedades (en libras mallorquinas)

Monasterio La Real ...................17

53.348

Cartuja de Valldemossa................28

Convento Sto. Domingo ...............33

Convento del Carmen ...................28

119.730

Convento La Merced ...................25

116.947

Convento Sto. Espíritu...............26

23.146

Convento Socorro ........................43

21.151

Convento San Francisco .32

TOTAL .....................232

(2) VILAR P. Estructures de la societat espanyola cap al 1750. Algunes lliçons dél Cadastre de Ensenada. «Recerques》 I, (Barcelona), 1970 p. 13.

(3) VALIENTE, T. El marr político de la desamortización en España. Barcelona, 1972, pp. 62-65.

(4) MUNAR, G. Les ordes religioses a Mallorca. Compendiosa història de la seva obra dins aquesta diócesi fins a l'any de la seva exclaustració. 1835, Fascicle I. Archivo Histórico Reino de Mallorca. (AHRM). 
Según A. Grasset de Saint-Sauveur, enviado de Napoleón en Mallorca, la Isla tenía un total de 3.259 eclesiásticos, representando un 2'39\% de la población total que calculaba en unos 136.000 habitantes $(1.002$ religiosos; 1.204 religiosas y 1.053 clérigos seculares) (7).

La riqueza del clero secular era también importante. Los diezmos significaban una de las fuentes mayores de ingresos de las principales parroquias. Su cuantía ascendía según un Expediente de 1773 a las siguientes cifras:

(En libras mallorquinas)

\begin{tabular}{|c|c|c|c|}
\hline Parroquias & Diezmos & Parroquias & Diezmos \\
\hline Manacor.. & .13 .000 & Felanitx... & .11 .454 \\
\hline Porreres.. & $\ldots 8.659$ & Bunyola.. & $\ldots 7.200$ \\
\hline Artà ......... & .6 .770 & Petra......... & .6 .472 \\
\hline Binissalem .. & .6 .420 & Castell Llubí & .5 .735 \\
\hline Binialí ........ &. .5 .558 & Pollença .... &. .5 .420 \\
\hline Esporles .. &. .4 .800 & Sineu ............ &. .4 .713 \\
\hline Calvià .... & .4 .400 & Sant Joan.. & ...4.096 \\
\hline Sta. María ... &. .3 .954 & Algaida....... & .3 .478 \\
\hline Sta. Margalid &. .3 .670 & Marratxi..... &. .3 .559 \\
\hline Selva.......... & ..3.400 & Inca ........... & ...3.260 \\
\hline Alcúdia ........ & .3 .060 & Sta. Eulalia & $\ldots 2.500$ \\
\hline Sant Jaume. & .2 .400 & Andrax....... & ...1.949 \\
\hline Campanet.... & $\ldots .1 .766$ & Valldemossa & $\ldots 1.400$ \\
\hline Campos ....... & $\ldots .1 .041$ & & \\
\hline
\end{tabular}

Pero sin duda era la Mesa Capitular de la Seo de Palma quien ingresaba cantidades superiores a las de las parroquias. En este sentido son elocuentes las cifras sacadas de las Actas capitulares en concepto de los diezmos del grano, vino, aceite, azafrán y ganado y de los censos, laudemios, préstamos y alodios, correspondientes a los años 1805-1813:

(5) Empadronamiento general de la población de esta ciudad y su término formado en el año 1787. Archivo Municipal de Palma de Mallorca (AMPM), Legajo 640, Expediente $n^{\circ}$ 4378.

(6) Bens que poseien els frares segon Catastre en Miscelánea histórica mallorquina, vol. II (manuscrito) $n^{\circ}$ 28. Archivo Monasterio La Real de Palma (AMLRP).

(7) GRASSET DE SAINT SAUVEUR, A. Viaje a las /slas Baleares y Pithusas escrito durante los años 1801 a 1805 por (...), Tomo I, Palma, 1952, p. 49.

(8) Expediente formado sobre reparos de las Iglesias parroquiales del Reino de Mallorca según orden de $S$. Magestad. (AMLRP), Palma, 1793, $172 \mathrm{f.}$ 


\begin{tabular}{|c|c|c|c|c|}
\hline Años & Ingresos & Gastos & Diferencia & $\begin{array}{c}\text { Ingresos de cada } \\
\text { uno de los } \\
24 \text { canónigos }\end{array}$ \\
\hline 1805 & (sueldos mallorquines) & $\begin{array}{c}\text { orquines) } \\
4.897 .682\end{array}$ & 19.313 .298 & 621.058 \\
\hline 1806 & 15.268 .025 & 4.496 .447 & 10.771 .578 & 448.816 \\
\hline 1807 & 15.128 .357 & 4.558 .069 & 10.570 .360 & 440.431 \\
\hline 1808 & 16.468 .517 & 4.561 .669 & 11.906 .848 & $490.069 ?$ \\
\hline 1809 & 8.343 .589 & 4.540 .430 & 3.803 .161 & 158.464 \\
\hline 1810 & 17.054 .602 & 1.894 .955 & 15.159 .647 & 631.651 \\
\hline & 16.716 .265 & 3.276 .104 & 13.440 .181 & $559.947 ?$ \\
\hline 1813 & 14.739 .024 & 2.986 .216 & 11.752 .862 & 489.703 \\
\hline
\end{tabular}

Para evaluer la riqueza del clero secular de Palma existe un documento de 1812, de capital importancia, referido a las cantidades asignadas a los eclesiásticos como contribución extraordinaria de guerra. El estamento eclesiástico de las siete parroquias de la ciudad y término lo componían 355 miembros del clero secular, 57 del regular, 12 caballeros de órdenes militares y 13 familiares del Tribunal de la Inquisición. Su distribución por parroquias era la siguiente:

\begin{tabular}{|c|c|c|c|c|c|}
\hline Parroquia & $\begin{array}{l}\text { Clero } \\
\text { secular }\end{array}$ & $\begin{array}{l}\text { Id. } \\
\text { regular }\end{array}$ & $\begin{array}{c}\text { Ordenes } \\
\text { milit. }\end{array}$ & Sto. Oficio & Total \\
\hline Almudaina & 24 & - & 1 & 2 & 27 \\
\hline Sta. Eulalia & 148 & 18 & 2 & $\overline{5}$ & 173 \\
\hline Sta. Cruz & 40 & 4 & 5 & -- & 49 \\
\hline San Jaime & 47 & 2 & 3 & 2 & 54 \\
\hline San Miguel & 54 & 23 & -- & 2 & 54 \\
\hline San Nicolás & 39 & 10 & 1 & 2 & 52 \\
\hline Término ciudad & 3 & -- & -- & -- & 3 \\
\hline Total & 355 & 57 & 12 & 13 & 437 \\
\hline
\end{tabular}

El citado repartimiento se hizo partiendo de que de cada 100 libras de capital correpondian 11 sueldos de contribución. Las cifras relativas al clero regular no reflejan la cuantía de los bienes que poseían, pues solamente contribuian algunos miembros de la orden. Hay que destacar, sin embargo, las elevadas cifras correspondientes a las órdenes militares

(9) Actas capitulares vol. 1 (1805-1807); vol 2 (1808-1811); vol. 3 (1811-1813). Archivo Capitular de la Seo de Mallorca (ACSM). 
(asi por ejemplo Tomás de Veri tenía un capital valorado en 86.878 libras, 3 sueldos y 2 dineros), y a las personas vinculadas al Tribunal de la Inquisición, cantidades todas ellas superiores al clero secular:

\begin{tabular}{|c|c|c|c|c|}
\hline Parroquia & Clero secular & Id. regular & Ordenes milit. & Sto. Oficio \\
\hline \multicolumn{5}{|l|}{ Almudaina } \\
\hline $\begin{array}{l}\text { capital (en sueldos) } \\
\text { - contribución (id.) }\end{array}$ & $\begin{array}{r}9.579 .317 \\
52.590\end{array}$ & $\begin{array}{l}--ー- \\
----\end{array}$ & $\begin{array}{r}13.167 .779 \\
72.422\end{array}$ & $\begin{array}{r}4.650 .503 \\
25.026\end{array}$ \\
\hline \multicolumn{5}{|l|}{ Sta. Eulalia } \\
\hline - capital & $\begin{array}{r}35.265 .460 \\
198.666\end{array}$ & $\begin{array}{r}1.211 .438 \\
971 ?\end{array}$ & $\begin{array}{r}85.414 .966 \\
467.782\end{array}$ & $\begin{array}{r}3.248 .190 \\
17.864\end{array}$ \\
\hline \multicolumn{5}{|l|}{ Santa Cruz } \\
\hline - contribución & $\begin{array}{r}4.795 .897 \\
25.928\end{array}$ & $\begin{array}{r}1.824 .480 \\
836 ?\end{array}$ & $\begin{array}{r}67.258 .690 \\
345.847\end{array}$ & $\begin{array}{l}---- \\
----\end{array}$ \\
\hline \multicolumn{5}{|l|}{ San Jaime } \\
\hline capital & $\begin{array}{r}38.040 .984 \\
215.853\end{array}$ & $\begin{array}{r}741.000 \\
4.075\end{array}$ & $\begin{array}{r}29.789 .906 \\
163.846\end{array}$ & $\begin{array}{r}50.849 .280 \\
280.634\end{array}$ \\
\hline \multicolumn{5}{|l|}{ San Nicolás } \\
\hline capital & $\begin{array}{r}4.920 .844 \\
31.714\end{array}$ & $\begin{array}{r}1.286 .500 \\
7.075\end{array}$ & $\begin{array}{r}20.850 .758 \\
114.678\end{array}$ & $\begin{array}{r}13.810 .336 \\
76.396\end{array}$ \\
\hline \multicolumn{5}{|l|}{ San Miguel } \\
\hline - contribución & $\begin{array}{r}11.523 .802 \\
63.360\end{array}$ & $\begin{array}{r}2.428 .932 \\
13.239\end{array}$ & $\begin{array}{l}---- \\
----\end{array}$ & $\begin{array}{r}2.122 .818 \\
11.692 \\
(10)\end{array}$ \\
\hline
\end{tabular}

Según B. Barceló el clero regular de las Baleares poseía a principios del siglo $\mathrm{XIX}$, además de un gran número de fincas urbanas, 139 fincas rústicas cuya productividad era muy baja y las técnicas de explotación muy atrasadas (11). Su situación era crítica puesto que las malas cosechas de principios de siglo disminuyeron sus ingresos, además de las cargas que tuvieron que soportar para financiar las Guerra de la Independencia. Que su economía era deficitaria, sumando más los gastos que los ingresos, se comprueba por ejemplo analizando el libro de Recibo del convento de San Francisco de Paula (mínimos) de Palma durante los años 1808-1814. Los ingresos, contabilizados trimestralmente (excepto el tercer trimestre cuyos datos no constan), proceden de los censos, misas y en concepto de sacristía. Los gastos eran utilizados preferentemente para atender las necesidades de la comunidad:

(10) Estado eclesiástico de la capital y su término (...) Palma, 1812. AHRM, D-771. $47 \mathrm{f}$.

(11) BARCELO I PONS, B. El segle XIX a Mallorca. Palma, 1964, p. 12. 


\begin{tabular}{|c|c|c|c|}
\hline Año & Ingresos & Gastos & Déficit \\
\hline \multicolumn{4}{|c|}{ (en sueldos) } \\
\hline 1806 & 757.492 & 799.735 & -42.243 \\
\hline & 724.755 & 780.116 & -55.361 \\
\hline & 688.788 & 779.239 & -90.451 \\
\hline & 670.014 & 677.558 & -7.544 \\
\hline & 693.102 & 819.660 & -126.558 \\
\hline & 840.006 & 837.933 & +2.073 \\
\hline & 857.573 & 990.800 & -133.227 \\
\hline & 879.631 & 964.208 & -84.577 \\
\hline 18 & 733.324 & 859.609 & -126.285 \\
\hline
\end{tabular}

Aunque el poder económico del estamento eclesiástico era importante, sin embargo sus riquezas estaban muy mal repartidas. Existían grandes diferencias entre el clero regular y el secular, e incluso dentro de éste. El obispo de Menorca puso de manifiesto esta situación en su respuesta a la consulta hecha por la Junta Central sobre las futuras Cortes: "Al paso que estos afanados pastores y otros pasan mil fatigas trabajando en el pasto espiritual de sus ovejas sin tener muchos de ellos apenas congrua con que sustentarse, vemos por otra parte muchos de los eclesiásticos primeros, arriba citados, vemos dignidades y prebendados apenas sin trabajo, llenos de monstruosas rentas y conveniencias temporales» (13).

Delante de la nueva situación política creada por la Guerra de la Independencia las órdenes religiosas tenían dos caminos: o arruinarse sosteniendo el Antiguo Régimen, o exponerse a perderlo todo si se ponían al lado de las nuevas tendencias. Los estudios del profesor J. Fontana han puesto de manifiesto, como se confirma en el caso de Mallorca, el proceso de decadencia y ruina de la economía monástica a finales del Antiguo Régimen:

«(...) el clero regular era hostil al liberalismo porque trataba de arrebatarle sus riquezas y posición privilegiada, pero pardójicamente - afirma - los absolutistas hubieran acabado igualmente con sus riquezas de manera más lenta, puesto que el gobierno no podía sobrevivir sin obtener mayores recursos tributarios del estamento eclesiástico» (14).

(12) Libro de Recibo del convento de San Francisco de Paula de la presente ciudad de Palma (1805-1818). AHRM. Sección conventos, C-62.

(13) Citado por Suárez, F. Cortes de Cádiz. Informes oficiales sobre Cortes. Baleares. Ediciones Universidad de Navarra, 1967, p. 274.

(14) FONTANA, J. La quiebra de la monarquía absoluta. Barcelona, 1971, pp. 162 y s. 
Esta situación motivó que las órdenes religiosas se lanzasen a una acción política en favor del absolutismo, sobre todo a partir de 1813. Un hecho iba a producir la culminación de la oposición entre ambos grupos: la abolición del Tribunal de la Inquisición por las Cortes $(5$ enero de 1813).

La polémica abierta en torno a la Inquisición era la primera discusión ideológica de la España contemporánea, de la que se hicieron eco los periódicos malloquines. Al publicarse en Palma el decreto de extinción del citado Tribunal, el 25 de abril de 1813, el edificio inquisitorial fue invadido por una masa de gente, muchos de ellos descendientes de los judios mallorquines (xuetes) que durante siglos habían sufrido la humillación de este Tribunal.

Como reacción los obispos de Lérida y Pamplona, refugiados en Mallorca y firmantes de la célebre Instrucción pastoral de 1812 de clara oposición al gobierno liberal, protestaron ante las Cortes por su extinción, pues era a su parecer «el remedio más eficaz que tenemos en el día para salvar a da patria» (15). Mientras, un grupo de intelectuales, militares, comerciantes y libreros dirigieron a las Cortes una efusiva felicitación por haber tomado tal decisión, en un escrito fechado en Palma el 14 de febrero de 1813. Entre los 120 firmantes de este documento sobresalen los liberales I. de Antillón, I. de Montís, J. Terrers, V. Terrers, general Villalba y M. de Victorica (miembros de la Sociedad de Amigos del País y Fiscal del desaparecido tribunal). En estos términos se dirigían a las Cortes:

"Señor. Nada estaba seguro, existiendo el tenebroso tribunal de la Inquisición, que V. M. acaba de abolir. Instrumento de zozobra política, enemigo declarado de la ilustración, perseguidor de los talentos y aun de la virtud, y sobremanera fuerte para perder a quien se le oponía o disgustaba; quedaba vacilante y mal cimentado el edificio político que V.M. exigiera a tanta costa sobre las ruinas abominales del despotismo» (16).

El 22 de abril el Jefe político A. Desbrull comunicó al gobernador de la Mitra y al presidente del Santo Oficio el decreto de su extinción para que se publicase en todas las Iglesias según lo ordenado por las Cortes. Dos días después, el 24, se leyó el citado decreto ante los empleados de este Tribunal.

(15) Representación sobre el tribunal de la Inquisición. Palma, 16 de mayo 1813. Imprenta F. Guasp, p: 287.

(16) Felicitación a las Cortes generales y extraordinarias. Palma, imprt. M. Domingo, 1813. 
La reacción por parte del partido servil ( «los seminaristas») no se hizo esperar. El día 22 el Seminario cristiano político de Mallorca publicó el dictamen y voto del diputado Llaneras que había defendido el 21 de enero de este año. Días después insertó este periódico el Memorial de lōs gremios al Cabildo y Jefe político de la ciudad demostrando que la medida tomada por las Cortes era impopular. Por su parte los regiliosos predicaron desde el púlpito de las Iglesias contra los liberales («auroristas», que editaban la Aurora patriótica mallorquina), induciendo a las masas populares a levantarse contra el orden cosntituido. Los desórdenes culminaron en los llamados «alborotos» del 30 de abril.

Que los frailes utilizaron el púlpito para adoctrinar y soliviantar a las masas, lo prueba la abundante documentación de la época consultada. El obispo de Mallorca D. Bernardo Nadal, que se hallaba en Sóller en el mes de febrero restableciéndose de una enfermedad, había insinuado al Vicario General de la diócesis la conveniencia de publicar un edicto tratando el problema de las predicaciones:

"Una de las cosas que convendría poner en él - afirma-, sería el qué y el cómo se ha de predicar, suspendiendo ipso facto in perpetuum de predicar al que en el sermón se meta en tratar de asuntos políticos, militares, y otros inconexos. Si quieren esos frailes, verdugos de sí mismos, impugnar la Aurora u otro papel, tienen expedito el uso de la imprenta» (17).

Siguiendo estas directrices el Vicario General dirigió un edicto a los rectores y vicarios de la diócesis, con fecha 6 de marzo de 1813, advirtiéndoles que no debían utilizar las predicaciones para atacar el orden establecido:

«(...) sean fieles dispensadores de la palabra de Dios haciendo amable la predicación y de ninguna manera odiosa, entretejiendo expresiones o discursos impropios, que no conducen para la edificación de los oyentes, sino para transtornar el orden social» (18).

Por su parte los Alcaldes del Ayuntamiento de Palma dirigieron un oficio al Vicario General, con fecha 23 de abril de 1813, comunicándole los abusos cometidos por un grupo de religiosos en sus predicciones cuaresmales:

"(...) apenas se oye sermón, en el que no se trate de amedrantar al público con el próximo peligro de perder la fe; lo cual cede en descrédíto

(17) Carta al Vicario General de fecha 14 de febrero de 1813. Palma, imprenta Villaloga, 1813, p. 9.

(18) Edictos del muy llustre señor Vicario General, gobernador del obispado de Mallorca. Reimpreso en Palma, imprt. de Brusi, 1813, pp. 8-9. 
del gobierno, y de las autoridades, que se hallan encargadas de la conservación de un bien estimable» (19).

El 26 de abril el Vicario General ordenó al Jefe político, Alcalde del Ayuntamiento y Juez de letras recoger cuantos escritos fuesen contrarios a la Religión y al Estado. El Jefe político dirigió un bando al pueblo en este sentido con estas palabras:

"I(...) se han tomado todas aquellas providencias de acuerdo con el vigilante pastor eclesiástico para desterrar toda perniciosa ponzoña y no permitir corran las aguas inmundas de escritos contrarios a la Religión y buenas costumbres, y mi autoridad obrará con firmeza en esta ocasión» (20).

El Vicario General calificó estos hechos de «abuso del ministerio de la predicación", haciendo responsables a los Provinciales de las predicaciones de sus subordinados. El Obispo se había visto obligado en el mes de febrero a retirar las licencias de predicación a dos religiosos y antes de marchar a Cádiz exhortó al padre Manzaneda, que debía de predicar en la catedral el domingo de Pascua de Resurrección, a atenerse a las normas establecidas y no atacar al periódico la Aurora patriótica malloquina.

\section{2. - FUENTES DOCUMENTALES}

Antes de analizar los sucesos ocurridos el 30 de abril conviene tener presente las distintas fuentes documentales existentes. La versión oficial, tanto civil como eclesiástica, tiende a resaltar la espontaneidad y no premeditación de tales hechos. Los documentos más importantes que reflejan esta tendencia son el Oficio del Jefe político de Palma Antonio Desbrull, el artículo comunicado al periódico gaditano El procurador general de la Nación y del Rey (26 de junio 1813) del diputado mallorquín Antonio Llaneras, el Informe de la Diputación Provincial de Mallorca al Consejo de Regencia y las cartas del Cabildo y de los superiores de las órdenes religiosas al Obispo. Contrariamente a la versión oficial, el Informe del Juez de $1^{\text {a }}$ Instancia de Palma (I. Pablo Sandino) enviado a las Cortes, la Acusación Fiscal y los análisis de algunos periódicos gaditanos y mallorquines calificaron los sucesos de «alborotos populares» contra el gobierno establecido. Las discrepancias son aún mayores entre ambos cuando intentan explicar sus causas.

(19) Copia de la carta circular que ha pasado el muy ilustre señor Vicario General a los superiores de las órdenes regulares. 28 abril 1813. Imprt. M. Domingo, Palma.

(20) Impresos (1808-1813). AHRM, D-635. 
En la relación de los hechos materiales las fuentes discrepan muy poco. El viernes 30 de abril se celebraba una fiesta religiosa en el convento de Sta. Catalina de Palma sito en la calle de San Miguel. Al pasar por allí el médico Valentín Terrers, regidor del Ayuntamiento que había suscrito la Felicitación a las Cortes por la abolición del Tribunal de la Inquisición, fue insultado y agredido con piedras por un grupo de gente que se encontraba en este lugar, teniendo que refugiarse en una casa de las inmediaciones. Enterado del suceso el Jefe político, pasó aviso al Gobernador Militar quien apaciguó los ánimos y puso a salvo en lugar seguro a Terrers. El segundo Alcalde D. Gaspar Coll tomó declaraciones de lo ocurrido a los presentes sin llegar a conclusiones claras. Este mismo día por la noche en la plaza de San Antonio se repitieron los insultos y agresiones contra los liberales Jaime Lapuente y Agustín Lladó. Al hacer acto de presencia la fuerza pública detuvo a dos muchachos de 10 y 15 años (21).

Ante las denuncias hechas por el médico Terrers el 8 de mayo, y la

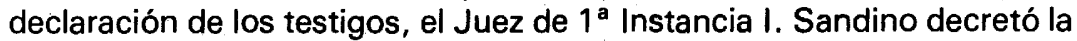
prisión de los religiosos Daniel de Manzaneda, Nicolás Prohens, Miguel Abraham, Julián Bordoy y Antonio Gual el día 9, el 13 la de los eclesiásticos Bartolomé Soler Roig y Pablo Miró y el 28 de julio la del padre Strauch. Según la Acusación Fiscal estos religiosos eran los causantes directos de tales sucesos:

«(...) con sus expresiones sediciosas aparecian con todas las señales de unos facciosos, que no sólo habían influído a dichos alborotos, sino que trabajaban de continuo para una revolución» (22).

Informado el Gobierno de lo ocurrido por el secretario interino de Gobernación, ordenó al Juez de primera instancia abrir un sumario contra los promotores de tales sucesos y averiguar sus causas. La orden estaba fechada en Cádiz el 25 de mayo (23).

Pronto se divulgó la noticia de los «alborotos» en los periódicos gaditanos, principalmente a través de El Tribuno del pueblo español, conocido por su exaltado liberalismo, y El Redactor general, que recogía cuantas noticias interesantes se publicaban en otros periódicos (24). Según El Tribuno el ufanatismo de los frailes» que en sus predicaciones «alucinaban y seducian al pueblo», era la causa de este hecho

(21) Oficio del Sr. Jefe Político. Palma 1 mayo 1813 en La verdad sostenida por las leyes. Palma, imprt. A. Roca, 1814, pp. 20-21.

(22) FERRA, J. Acusación a los reos de los alborotos del 30 de abril último (...) Palma 29 de octubre de 1813 , imprt. M. Domingo, 1813, p. 5.

(23) Suplemento a la Aurora patriótica mallorquina de 17 de junio de 1813.

(24) SOLIS, R. El Cádiz de las Cortes, Madrid, 1969, pp. 413 y 434. 
«sedicioso». La participación popular se debía «al embrutecimiento que nos encontramos por el predominio que ejercen entre nosotros los frailes» (25).

Las versiones que ambos periódicos gaditanos dieron de los sucesos no fueron del agrado del diputado mallorquín Antonio Llaneras. Vinculado al partido servil, se había opuesto en el Congreso a la libertad de imprenta, sostuvo la inmunidad eclesiástica y se declaró partidario tenaz de la Inquisición (26). Vitoreado en Palma a su regreso en 1814, fue recompensado con una canongía en la catedral por los servicios prestados a la causa absolutista. Pidió que la Comisión de Justicia tratase el asunto de los «alborotos» antes que el Consejo de Regencia y protestó por el procedimiento que se había seguido. Según él los causantes de estos sucesos no habían sido las autoridades, clero regular o secular, nobleza o inmigrados; el carácter "apacible» de los mallorquines y el «orden social existente" se vieron perturbados por la aparición del periódico la Aurora patriótica mallorquina, al difundir uperniciosas máximas de la irreligión y de la inmoralidad que tanto desorden introdujeron en Francia» y divulgar el "Pacto Social» de Rousseau. Por ello los religiosos criticaron en sus predicciones estos impresos, no habiéndose producido ningún incidente cuando se publicó el decreto de extinción de la Inquisición. Los sucesos de abril fueron «momentáneos» y sin premeditación, por lo que no debian de calificarse de «tumulto o levantamiento popular» (27). Criticó duramente el encarcelamiento de los religiosos ordenado por el Juez y a su juicio el problema de los "alborotos» se aclararía "cuando se supiese con certeza quiénes fueron los muchachos que tiraron piedras y quiénes habían detrás de ellos» (28). Sin embargo no negaba la posibilidad de que hubiese participado en ellos algún eclesiástico:

«(...) y estas son las ocurrencias, que tan arbitraria e injustamente han querido exagerar los periódicos de Cádiz sólo con el objeto de denigrar y vilipendiar al estado eclesiástico, y con especialidad a los regulares, hechos el objeto de los fulminantes rasgos de Napoleón, de sus satélites y de todos los Napoleonistas españoles, empeñados en regene-

(25) Reproducido en el Semanario cristiano político de Mallorca, $n^{\circ} 57,19$ agosto 1813 , p. 384.

(26) Dictamen sobre Tribunal del Santo Oficio de D. Antonio Llaneras, en Semanario cristiano político de Mallorca 23 abril 1813.

(27) LLANERAS, A. Artículo comunicado en el Procurador general de la nación y del rey del sábado 26 de junio de 1813. Reimpreso en Palma, 1813, $8 \mathrm{p}$.

(28) LLANERAS, A. Demostración de la verdad del manifiesto de (...). Palma, imprt. Brusi, 1813, p. 24. 
rar á nuestra nación a la francesa. Podría ser, que algún eclesiástico, o del estado lego hubiese tenido parte y cooperado de algún modo a tales públicos acontecimientos; castíguense los que hayan sido; es justo; á nadie es lícito, quanto menos á los eclesiásticos, el cooperar ni directa, ni indirectamente a que se perturbe el órden y la tranquilidad pública, de la que suelen resultar muchos y gravísimos daños a la religión al estado y á los particulares») (29).

La versión de Llaneras fue criticada por El Tribuno y por el propio I. Pablo Sandino, que intentó defender su honor difamado, poniendo en evidencia el interés de Llaneras en proteger a los alborotadores (30).

En la sesión de Cortes del 14 de junio de 1813 se leyó el Informe del Juez I.Pablo Sandino. En él se explicaba que un grupo de liberales habían sido injuriados y apedreados, provocando «alborotos populares y sediciosos» (31). Como réplica la Diputación Provincial de Mallorca dirigió un comunicado al Consejo de Regencia. Su versión coincidía con la del Jefe político y la del diputado Llaneras: la aparición del periódico la Aurora patriótica mallorquina había turbado el carácter pacífico de los mallorquines; los sucesos nunca fueron premeditados y al no haber habido derramamiento de sangre o lucha armada no merecian los calificativos de «alborotos, conmociones populares y sediciones» (32).

Por su parte el Cabildo y los superiores religiosos informaron de lo sucedido al Obispo Nadal que se encontraba en Cádiz. Su objetivo era comunicarle «el estado infeliz de los Regulares de esta diócesis». Reconocian que algunos de ellos habían predicado durante la Cuaresma contra algunos escritos, principalmente el «Pacto Social» de Rousseau, y aludían al decreto de extinción de la Inquisición que se había publicado con normalidad en la ciudad. Esta era la versión de los hechos:

"(...) algunos muchachos incomodaron una $u$ otra vez a algunos de ellos (los firmantes de la Felicitación), gritando en su seguimiento, sin que sucediese más bullicio o conmoción popular, ni hubiese efusión de sangre o les sucediese a los acosados daño alguno; sin embargo este pequeño disturbio ha querido atribuirse a los Regulares, especialmente a los predicadores» (33).

(29) LLANERAS, A. Artículo comunicado, o.c. p. 7

(30) El Tribuno del pueblo español $n^{\circ} 26$

(31) El Semanario cristiano político reprodujo esta sesión en el $n^{\circ} 53$ de julio de 1813 , pp. 341-343.

(32) La diputación provincial al Consejo de Regencia en Semanario cristiano político 18 nov. 1813.

(33) Cartas del Cabildo catedralicio y Prelados ordenes Regulares al Obispo. (...). Palma, imprt. F. Guasp, 1813, pp. 4-5. 
Finalmente le exhortaban en su escrito a que protegiese a los religiosos encarcelados.

El Obispo les contestó, con fecha 18 de julio de 1813, asegurándoles que haría las gestiones oportunas al respecto y que pronto regresaría a la diócesis para «impedir ulteriores males», no debiendo temer por el aspecto religioso en los debates de las Cortes, ante las calumnias que se habían extendido en este sentido (34).

El Vicario General salió al paso de una supuesta carta del Obispo, de fecha 3 de julio, contestando a la que le habían dirigido los superiores de las órdenes religiosas con fecha 8 de mayo, en la que se afirmaba que había sido obligado violentamente a escribir el edicto de 28 de abril sobre la predicación. Rebatió tales acusaciones manifestando que había seguido los consejos del Obispo con el que siempre había estado de acuerdo (35).

Los religiosos Strauch y Manzaneda, representantes de la línea más reaccionaria, criticaron los edictos del Vicario General sobre la predicación. Straucb, autocalificándose de "apologista de los predicadores», afirmó que la Aurora, "manantial de impiedad y germen de sedición», y los que firmaron la felicitación a las Cortes por la extinción del Tribunal de la Inquisición, fueron los causantes de los «alborotos» (36). Para Manzaneda era una calumnia afirmar que los religiosos habían sido los causantes de los sucesos de abril:

«Es una calumnia decir que nosotros hemos seducido al pueblo, que le hemos aconsejado el tumulto y la sedición, que hemos hecho fieros sus ánimos cuando sólo hemos predicado la paz de Jesucristo y la obediencia a las autoridades» (37).

Según la Acusación Fiscal las causas remotas de los sucesos de abril se deben buscar en las críticas que el Semanario cristiano politico había dirigido contra la Aurora, haciendo aparecer a sus seguidores como irreligiosos:

«(...) se empeñaron los redactores del primero (Semanario) en hacer odiosos a los del segundo (Aurora) y a todos sus adictos, excitando de

(34) Cartas del Cabildo (...), o.c. p. 5.

(35) Reflexiones sobre una carta que se atribuye al señor Obispo de Mallorca (...) Palma, imprt. Villalonga, 1813.

(36) STRAUCH, R. Ensayo de un cotejo de la carta del vicario general a los superiores órdenes religiosas (...). Palma, imprt. F. Guasp, 1813, pp. 4 y 7.

(37) MANZANEDA, D. La verdad o la conducta de los predicadores de esta ciudad de Palma de Mallorca vindicada. Palma, imprt. Brusi, 1813. 
este modo la formación de dos partidos, graduando el suyo de cristiano y religioso, y al contrario, al de los afectos al gobierno, de irreligioso» (38).

La causa inmediata se debió a las predicaciones cuaresmales de los religiosos (39).

De los 23 acusados por el fiscal en los alborotos de abril, 11 pertenecían al clero regular, 4 al secular y el resto eran civiles. Por su gran interés resumo las acusaciones que se les hizo a cada uno de ellos:

- Frco. Marroig, capuchino, por haber escrito unas décimas infamatorias contra los que firmaron la Felicitación a las Cortes, calificándolos de «libertinos, protestantes, luteranos, francmasones, afrancesados $y$ contrarios a la fe y a la religión" (40).

- Miguel Abraham, agustino, por aprobar en una homilía los insultos contra el regidor Valentín Terrers y su hijo, a los que calificó de herejes.

- Nicolás Prohens, prior de los agustinos, por permitir las expresiones del anterior.

- Miguel Tomás Riusech, por encubrir al padre Abraham.

- Jaime Coll, tejedor de profesión, por ser cabecilla material de los «alborotos» de la mañana del $\mathbf{3 0}$ de abril.

- Jaime Sancho, cabo de artillería, por participar en los «tumultos» contra Valentín Terrers.

- José Moya, por maltratar con piedras y un palo al aprendiz Agustín Lladó en los «tumultos» de la noche del $\mathbf{3 0}$ de abril. te.

- Pablo Miralles, por participar en el «tumulto» contra Jaime Lapuen-

- Antonio Gual, religioso mínimo, autor de unos pașquines incitando a dar muerte al liberal Juan Cantó.

- José Roig, religioso mercedario, por afirmar que la Constitución española estaba prohibida en Inglaterra bajo pena de muerte y manifestar que quien leyese el periódico la Aurora estaba excomulgado.

- Andrés Vives, zapatero, por tratar de hereje a Jaime Lapuente.

- Bartolomé Soler, deán de la catedral de Tarragona, sospechoso de ser uno de los agentes de monseñor Gravina, nuncio de S.S. que tramaba un complot desde Cádiz contra el Gobierno. Con ocasión del decreto de extinción del Tribunal de la Inquisición había dicho en la concurrida plaza de Cort que en Cádiz había habido una revolución «en la que había

(38) Acusación Fiscal, o.c. p. 6.

(39) Acusación Fiscal, o.c. p. 6.

(40) Acusación Fiscal, o.c. p. 9. 
corrido sangre» y era necesario que ésta estallase en Mallorca poniéndose él a su frente (41).

- Pablo María de Miró, maestrante de Granada, por aprobar las expresiones del anterior.

- Julián Bordoy, dominico, por proferir expresiones induciendo a "desobedecer, despreciar y desacreditar a las legítimas autoridades», y afirmar que se restablecería de nuevo la Inquisición mediante una «revolución popular» (42).

- Domingo Vidal, por afirmar que el gobierno de las Cortes no era legítimo.

-Domingo Lladó, religioso, por haber afirmado en un sermón en la Iglesia de Santa Eulalia que las ideas de igualdad trastocaban el orden social, equiparando a los liberales con «los revolucionarios franceses» (43).

- Miguel Lladó, religioso, por oponerse a la Constitución.

- Antonio Torregrosa y Matías Coll, sacerdotes, por proteger a los muchachos de los «alborotos».

- Jorge Mesías, miembro del extinguido Tribunal de la Inquisición, por luchar por su restablecimiento.

- Jaime Mudoy, sacerdote, rector de la Iglesia de Sta. Eulalia, por desacreditar en un sermón los decretos del Vicario General y la abolición de la Inquisición.

- Daniel Manzaneda, religioso capuchino, uno de los principales agentes y promotores de la "revolución que se preparaba en Palma», que debía de estallar la Pascua de Resurrección o el día que se publicase el decreto de extinción de la Inquisición, o cuando hubiese noticia de que hubiese sucedido en Aragón o Cataluña». Cuatro eran las acusaciones contra él: 1) haber formado un grupo de gente para atacar al periódico la Aurora; 2) mantener correspondencia con gentes de las provincias de Cataluña y Aragón donde se esperaba una revolución contra el Gobierno; 3) preparar a unos cuantos individuos para que impidiesen la lectura en las Iglesias del decreto de extinción de la Inquisición y 4) haber afirmado en el semón pronunciado en la catedral el domingo de Resurrección que el enemigo interno era más temible que el del exterior.

Con estas palabras describe a este religioso:

«Manzaneda es el genio de la discordia, es un escandaloso, insubordinado y rebelde, un revolucionario, atrevido y público, un enemigo

(41) Acusación Fiscal, o.c. p. 25.

(42) Acusación Fiscal, o.c. pp. 33-34.

(43) Acusación Fiscal, o.c. p. 35. 
declarado del Estado, un fanático perturbador de la tranquilidad pública y un hombre perjudicalísimo en la sociedad» (44).

- Raimundo Strauch, franciscano, caracterizado por su «fanatismo convulsionario, abusando de la cátedra de la verdad, del ascendiente que le concede el hábito, de la sencillez y piedad del pueblo que le escucha». Había afirmado desde el púlpito de la Iglesia de San Nicolás, el 25 de marzo, que existía en la ciudad una conspiración contra el Trono y el Altar. Asimismo recomendó encarecidamente al pueblo la lectura de la Instrucción pastoral y el Preservativo del padre Rafael de Vélez. En resumen, "fue uno de los principales autores de la revolución que se intentaba, dando margen sus predicaciones a los alborotos del 30 de abril» (45).

Por su parte los abogados defensores alegaron la inocencia de los encausados. El abogado de Francisco Marroig reconoció que su defendido había escrito aquellas décimas pero negó su participación en los sucesos llamados impropiamente «alborotos, conmoción popular, sedición y conspiración» (46). La defensa de M. Abraham negó todas las acusaciones concluyendo que si hubo alguna conspiración «no fue de los regulares contra los felicitantes, sino de éstos, protegidos por otros más poderosos contra los frailes» (47). La incompetencia del Juez fue el argumento utilizado por el defensor de $\mathrm{M}$. Prohens, que negó las acusaciones hechas contra su defendido (48). Andrés Sard, defensor de M. Tomás y Riusech, pidió la absolución de su defendido alegando su enajenación mental (49). Los señores J. Pol, J. Moya, P. Miralles y A. Vives fueron defendidos por Gaspar Homs quien negó su participación en los sucesos de abril que tuvieron como origen «las respuestas de unos muchachos a las palabras del médico Terrers» (50). Mariano Ballester, defensor de A. Gual, negó las acusaciones que se le imputaban a su defendido, afirmando la incompetencia del tribunal por tratarse de un reli-

(44) Acusación Fiscal, o.c. pp. 43-54.

(45) Acusación Fiscal, o.c. pp. 55-57.

(46) POU, J. El supuesto coplero criado en las montañas de Lluch. (...). Palma, imprt.

F. Guasp, 1813, 28 p.

(47) POU, J. Defensa del padre Fr. Miguel Abraham (...). Palma, imprt. F. Guasp, $1814,39 \mathrm{p}$.

(48) POU, J. Salvación de la inocencia en la defensa del padre Fr. Nicolás Prohens (...). Palma, imprt. F. Guasp, 1814, 39 p.

(49) SARD, A. La distracción, defensa que presentó D. Miguel Tomás y Riusech. Palma, imprt. F. Guasp, 1814, 22 p.

(50) HOMS, G. Día grande de Mallorca. Defensa (...). Palma, imprt. F. Guasp. 1814, p. 18. 
gioso (51). M. Seguí, defensor de J. Roig, negó que los sucesos de abril no podían calificarse de "conmoción, alboroto y tumulto», puesto que lo ocurrido se reducía a «insultos contra personas particulares», declarando incompetente a la jurisdicción civil por tratarse de un religioso (52). El doctor José Roset, canónigo lectoral de la catedral de Tarragona, defendió a Bartolomé Soler, concluyendo con estas palabras: «(...) resulta insuficientemente probado que no hubo alborotos ni conmociones populares, ni cabezas de ellos, ni incitaciones públicas ni privadas, simplemente bullicios pueriles» (53). Miguel Seguí, abogado defensor de J. Bordoy, tras afirmar la ilegalidad y nulidad del proceso, la ineptitud de los testigos y la mala actuación del Juez, negó la existencia de alborotos o intentos de revolución, términos equívocos utilizados por el Juez (el concepto «alboroto» tiene una connotación jurídica de agravio armado contra el gobierno, por lo que en su opinión era mejor utilizar el término «tumulto» en su acepción popular) (54). Andrés Sard defendió a J. Mesías para quien pidió su absolución por ser inocente (55). Antonio Ros se encargó de la defensa de D. Manzaneda, acusado de ser uno de los principales promotores de los sucesos de abril. Después de hacer un pequeño historial de este religioso a su paso por Madrid, Andalucía y Mallorca, afirmó que su defendido sólo predicó contra las ideas de Rousseau, negando que tuviese contactos con la supuesta revolución de Aragón y Cataluña (56). El religioso R. Strauch se defendió él mismo, negó la existencia de alborotos y reiteró su oposición a su encarcelamiento alegando que el Juez no tenía ningún poder sobre él (57).

La prensa mallorquina, desde sus respectivas tendencias ideológicas, informó de los sucesos de abril analizando al mismo tiempo sus causas. El periódico la Aurora patriótica mallorquina, aunque no se editó desde el 29 de abril al 19 de mayo de este año por el ambiente hostil que existía en Palma, informó en números posteriores de los hechos. Consciente de que se utilizaba el púlpito para "clamar contra la libertad», denunció al padre Strauch por haber afirmado en un sermón que existía en Mallorca una conspiración contra el Trono y el Altar (58). Calificó los su-

(51) BALLESTER, M. Caridad perseguida pero sostenida y demostrada por Fr. Antonio Gual mínimo (...) Palma, imprt. S. Savall, 1814, 26p.

(52) SEGUI, M. La inocencia vindicada (...) Palma, imprt. F. Guasp, 1814, pp. 18-19.

(53) ROSET, J. La verdad sostenida por las leyes (...) Palma, imprt. A. Roca 1814, p. 24.

(54) SEGUI, M. La verdad desnuda (...) Palma, imprt. F. Guasp, 1813, p. 19.

(55) SARD, A. Triunfo de la inocencia (...) Palma, imprt. B. Savall, 1814, $31 \mathrm{p}$.

(56) ROS, A. Defensa del padre Daniel de Manzaneda (...) Palma, 1814, imprt. F. Guasp, 69p.

(57) STRAUCH, R. El fiscal fiscalizado (...) Palma, imprt. F. Guasp, 1813, 41p.

(58) Aurora patriótica mallorquina, $n^{\circ} 52,28$ marzo 1813, p. 322. 
cesos de "disturbios», pensando que algunos de sus lectores manifestarían su oposición al término utilizado por su moderación. Su causa principal había sido «los sermones sediciosos y otros escritos que se habían extendido por la ciudad» (59). Publicó íntegramente la versión difundida a través de "El Tribuno del pueblo español», de fecha 4 de junio de 1813, y las órdenes dadas por el gobierno al Juez de primera ins: tancia de Palma. Criticó con dureza el manifiesto del diputado Llaneras por su falta de veracidad, las cartas del Obispo de Mallorca dirigidas al Cabildo y a los superiores religiosos y la Representación que envió la Diputación de Mallorca al Consejo de Regencia acusando a la Aurora de los desórdenes producidos (60).

El Semanario cristiano político no añade nada a la versión oficial de los hechos, negando que hubiese "premeditación» en tales sucesos (61). Se idẹntificó totalmente con el Manifiesto de Llaneras, alabándolo con los siguientes términos:

«(...) los mallorquines deben estar muy agradecidos a este diputado por haber disipado las atroces calumnias y negras inoportunas que unos seres clandestinos que no se atreven a mostrar el hocico, les habian imputado en los forasteros periódicos Redactor y Tribuno, cuya reimpresión nos ha regalado generosamente la no menos forastera Aurora» (62).

Publicó íntegramente el escrito que la Diputación dirigió a la Regencia y criticó duramente el encarcelamiento de los religiosos por haberse quebrantado el fuero eclesiástico (63). A juicio de uno de sus lectores el Semanario todavía se había quedado corto en sus críticas (64).

La Antorcha calificó los sucesos de "conmociones populares» motivados por la utilización de la religión «para inflamar los ánimos de la multitud». Su causa hay que buscarla en la defensa de los privilegios de los religiosos:

"Al transmitir de una a otra generación la memoria de los sucesos ocurridos en esta ciudad en los primeros días de un mes eternamente memorable, la posteridad imparcial formará con exactitud el juicio adecuado de la buena o mala intención con que una porción de hombres, reunidos bajo una misma égida, ansiosos de sostener unos privilegios

(59) Aurora patriótica mallorquina, $\mathrm{n}^{\circ} 116,25$ nov. 1813, p. 323, nota 1.

(60) Aurora patriótica mallorquina. nos. 79, 90, 107 y 116.

(61) Semanario cristiano político de Mallorca, $n^{\circ} 46,3$ junio 1813, pp. 253-255.

(62) Semanario cristiano politico de Mallorca, $n^{\circ} 54,29$ julio 1813, p. 356.

(63) Semanario cristiano politico de Mallorca, $n^{\circ} 57$, 19 agosto 1813, pp. 383-388; id. 18 nov. 1813.

(64) Semanario cristiano político de Mallorca, $\mathrm{n}^{\circ}$ 45, 27 mayo 1813, pp. 240-244. 
arrancados a la barbarie de otros siglos, luchan con denuedo, y sostienen con imprudencia las proposiciones más atrevidas, más falsas y más injuriosas a las autoridades, $y$ a los individuos que no se acomoden a sus ideas) (65).

El análisis que hizo el Diario de Mallorca es muy similar al de la Aurora, los ataques se dirigían contra los liberales que habían firmado la Felicitación a las Cortes. Criticó también la versión de Llaneras por no representar la visión de todos los diputados mallorquines.

\section{3. - VALORACION}

Los historiadores que han estudiado este período de la historia de Mallorca han recogido en sus obras, según sus respectivas ideologías, las distintas versiones apuntadas. Para J. Llabrés los sucesos fueron una protesta clara por la extinción de la Inquisición (68); según M. de los Santos Oliver su causa se debió en parte a las predicaciones de los religiosos, aunque a su juicio no quedó probado el concierto previo ni el levantamiento tumultuario y colectivo contra la autoridad (69).

Para tener una idea de los alborotos antiliberales de 1813, presentados como insignificantes por las fuentes absolutistas y como una revuelta peligrosa para los liberales, es necesario tener presente toda la documentación que hasta la fecha no se había analizado con profundidad y rigor científico. De ella se deduce que los religiosos utilizaron las predicaciones para intentar un levantamiento del pueblo contra el gobierno constituído, desoyendo las directrices marcadas por el Obispo B. Nadal. Su participación en los sucesos del 30 de abril parece cierta, incluso los informes del diputado Llaneras y de los superiores de las órdenes religiosas no negaban la posibilidad de que hubiese algún religioso implicado.

Con los sucesos de abril culmina el enfrentamiento entre serviles y liberales. Los religiosos, utilizando la predicación y la imprenta difundieron entre el pueblo la imagen de que los liberales eran «irreligiosos» y por ello similares a los "revolucionarios franceses». Los "auroristas», conscientes de que los religiosos intentaban defender su posición social y sus privilegios, apoyaron el nuevo orden constitucional, acusándolos de ser los promotores de tales hechos. Los religiosos a través de los pe-

(65) La Antorcha, ${ }^{\circ} 1$, pp. 1-4.

(66) Diario de Mallorca, $\mathrm{n}^{\circ} 218,18$ agosto 1813, pp. 897-899.

(67) Diario de Mallorca, $n^{\circ}$ 454, 31 dic. 1813, pp. 1503-1506.

(68) Llabres Bernal, J. Noticias y relaciones históricas de Mallorca, siglo XIX, vol. 1. 1801-1820, Palma, 1958, pp. 391-392.

(69) DE LOS SANTOS OLIVER, M. o.c.p. 621. 
riódicos y predicaciones se opusieron a cuantos decretos dictaban las Cortes. Detrás de todo ello se esconde una cuestión económica, la oposición de las órdenes religiosas al constitucionalismo y a las ideas liberales nació porque no estaban dispuestos a transigir en su situación privilegiada. Ideas que apuntaba un escrito anónimo de la época:

«No parece creíble que en medio de las afliciones que nos rodean llegase el extravío de la razón en una de las clases de la sociedad que debe sus privilegios a la liberalidad de ésta (clero regular), hasta el extremo lastimoso de desconocerlo, $y$ de querer sobreponerse al soberano resistiendo sus decretos en materias políticas, desacreditando su autoridad en el pueblo, y provocando sediciones, tumultos y choques. Pero por desgracia nos hallamos en este terrible caso, y desde Galicia hasta Aragón, desde Mallorca a Pamplona el espíritu funesto de las discordias, el afán de conservar las riquezas incompatibles con la independencia nacional y su defensa, agita los corazones piadosos (...), se predica la desobediencia, y se ponen las armas en las manos del pueblo para que acabe con los defensores de sus derechos" (70).

Mallorca fue uno de los centros principales del pensamiento reaccionario español de la época. Maravillosamente retratada por el enviado de Napoleón en 1805 André Grasset de Saint Sauveur aparece como una tierra alejada de remedios, un lugar de castigo donde Jovellanos estaba exiliado por su oposición al omnipotente Godoy, una sociedad dominada por los religiosos donde sus habitantes estaban divididos en herméticas clases sociales. Mallorca era vista por los liberales como el baluarte del Antiguo Régimen. La llegada de I. de Antillón a la Isla, para ocupar el cargo de magistrado interino de la Audiencia, sirvió para aglutinar en torno a su persona al partido liberal mallorquín, representado por una serie de personalidades (Tomás de Veri, Guillermo Ignacio de Montís, el conde de Amayans, Antonio Desbrull, Miguel de Victorica, Esteban Bonet, Valentín Terrers, Tte. Coronel Ruiz de Pons, M. Domingo y la figura insigne del Obispo Nadal). Como en el resto de España la restauración absolutista fue recibida en Mallorca con gozo y alegría por los serviles. Al llegar la noticia desde Valencia (20 mayo 1814) se destruyeron todos los vestigios del liberalismo: se quitó la placa que daba nombre en Palma a la plaza llamada de la Constitución, colocando en su lugar el retrato de Fernando VII, y a continuación fueron quemados los periódicos y publicaciones liberales a los gritos de «iViva la religión, Viva Fernando VII y muera la exacrable constitución!»

(70) Política eclesiástica sobre la carta circular pasada por el vicario general gobernador del obispado de Mallorca a los superiores de las órdenes regulares. Palma, imprt. M. Domingo, 1813, pp. 1-2. 